\title{
Effects of an Advance Care Planning Training Program for Certified Palliative Care Nurses in Japan
}

\author{
Yoko Yahiro ${ }^{1,2}$ (D) Mika Miyashita ${ }^{1} \cdot$ Katsumi Nasu ${ }^{3}$
}

Accepted: 9 December 2021 / Published online: 28 January 2022

(c) The Author(s) 2021

\begin{abstract}
Education programs for certified palliative care nurses who promote advance care planning (ACP) for cancer patients are important, but not currently available in Japan. This study aimed to develop an educational program of ACP for certified palliative care nurses in Japan and evaluate its effectiveness. A program consisting of four modules was implemented for 60 certified palliative care nurses in the Kyushu, Chugoku, and Shikoku regions. Participants attended one training session, and 39 responded to a survey on changes in ACP practice and difficulties with cancer nursing 3 months after the intervention. The Wilcoxon signed-rank test was performed to compare data before and after the intervention. The results obtained showed an increase in dialogue on ACP among patients/families and healthcare professionals (mean before the intervention $=24.49$, mean after the intervention $=27.59, p=0.045$ ), and a significant decrease in the sense of difficulty with knowledge of and skills for ACP (mean before the intervention $=4.85$, mean after the intervention $=4.30, p=0.001$ ). More than $90 \%$ of the participants gave positive comments on the evaluation items such as understanding and satisfaction with the educational program and appropriateness of the contents. After attending the training program, participants' sense of difficulty with their knowledge of and skills for ACP decreased, and their practice of ACP increased. This program may promote the practice of $\mathrm{ACP}$ for cancer patients in the future.
\end{abstract}

Keywords Advance care planning $\cdot$ Cancer patients $\cdot$ Certified palliative care nurse $\cdot$ Education program $\cdot$ Japan

\section{Introduction}

Advance care planning (ACP) is a comprehensive process in which patients, their families, and healthcare professional share their concerns and values regarding future treatment and recuperation, and plan their care in preparation for a future decline in decision-making capacity [1]. ACP is characterized by the process of clarifying values and goals of care from the perspective of the patient's life as a whole,

Yoko Yahiro

y_yahiro@fukujo.ac.jp

Katsumi Nasu

nasu-k@yasuda-u.ac.jp

1 Department of Gerontological and Oncology Nursing, Graduate School of Biomedical and Health Sciences, Hiroshima University, Hiroshima, Japan

2 Faculty of Nursing Department of Nursing, Fukuoka Jogakuin Nursing University, Fukuoka, Japan

3 Department of Nursing, Faculty of Nursing Yasuda Women's University, Hiroshima, Japan and exploring how the patient will live in the future with the surrogate decision-maker and medical staff, rather than making individual decisions about treatment, life-prolonging procedures, and place of care [2]. ACP was introduced to Western countries in the 1990s, and not only increased patient satisfaction with care [3], but also reduced the mental burden on family members $[4,5]$. It also reduced the cost of treatment for patients with advanced cancer [6].

Awareness of the importance of ACP is increasing in Japanese cancer medicine [7, 8]. Approximately $30 \%$ of doctors and nearly $20 \%$ of nurses recognize that they are actually practicing ACP [9]. A barrier to ACP is the lack of knowledge and skills, with only about $20 \%$ of physicians and nurses trained in decision support for terminally ill patients [9], and decision-making regarding end-stage medical care is centered on the family. In addition, some nurses are not skilled at communicating "bad news" to patients and their families [10]. In order to promote the practice of ACP in Japan, it is necessary to educate medical professionals about ACP so that these barriers can be resolved. The effects of educational programs on ACP have been reported 
worldwide. Participants in a training program utilizing a communication model increased their self-efficacy for ACP [11]. Furthermore, participants in a targeted training program received education using role playing and case studies, and, as a result, the implementation rate of ACP increased from that before training [12]. It is necessary for those who practice ACP to systematically learn the knowledge and skills related to ACP. Training programs on ACP in Japan are "The End-of-Life-Nursing Education Consortium-Japan" (ELNEC-J) and "Education For Implementing End-of-Life Discussion" (E-FIELD). However, there is no training program in Japan where nurses can systematically learn knowledge and skills related to ACP.

ACP for cancer patients is performed through a team approach, and certified nurses are involved in the practice, guidance, and consultation in a specific nursing field. Certified palliative care nurses are the cornerstone of multidisciplinary collaborations and facilitate the practice of ACP as the medical professional closest to a patient's family. In order to apply ACP to more cancer patients in Japan in the future, it is essential to have certified palliative care nurses who have expertise in ACP palliative care, have high technical standards, and practice ACP as a team.

The purpose of this study was to develop a training program that enables systematic and practical learning of ACP in consideration of Japanese medical care and culture, and to determine the effectiveness of the training program developed for certified palliative care nurses who facilitate ACP.

\section{Methods}

\section{Development of a Training Program}

To select the contents of the training program, we reviewed ACP guidelines and models, training programs, and training programs related to communication [13-18]. The following topics were extracted: definition of ACP, knowledge of disease and treatment, ethics, legal basis, effectiveness of ACP, continuous follow-up, system construction, role of medical personnel, understanding of values, and communication. The program was structured to provide group education in 4 modules with 12 topics over $5 \mathrm{~h}$ in 1 day (Table 1 ). Modules 1 to 3 include basic knowledge of ACP and the role of nurses: NURSE (naming, understanding, respecting, supporting, exploring) [19]. A lecture was provided that included information on the communication model. NURSE is a model for communicating "bad news" at the time of cancer diagnosis, recurrence, or when aggressive treatment is difficult. It focuses on the emotions of the patient and family, with the goal of helping the patient cope with his or her own emotions. In Module 4, group work consisted of 5-6 people per group. In this training program, participants clarify and then resolve their issues in order to effectively practice ACP. Problem-based learning was used for decision-making in discussions with others. Module 4 was designed to allow participants to share their perceptions of barriers to ACP practice with group members, and to discuss solutions and goals for future action. All training was conducted by the researcher. All the training was conducted in person.

\section{Participants}

The selection criteria included certified palliative care nurses belonging to facilities in the Kyushu, Chugoku, and Shikoku regions, whose facility names and names were published on the official website of the Japanese Nursing Association. The sample size of the participants was planned to be a paired two-way ANOVA by setting an intervention group and a control group at the time of study planning. When calculated with effect size $f=0.25, \alpha=0.05,1-\beta=0.8$, and scale number 2 with $\mathrm{G} *$ Power, a total of 34 or more samples were required in the intervention group and the control group. Although five study participants in the control group responded at T0, no one responded at T2. Hence, the prepost test design was used for the intervention group, and the Wilcoxon signed-rank sum test was conducted to verify the effects of the intervention. As a result of setting effect size $f=0.5, \alpha=0.05,1-\beta=0.8$ with $\mathrm{G}^{*}$ Power, a sample size of 35 or more was required. The number of participants in this study was 39 , which was sufficient for analysis.

\section{Procedure}

Information was provided to 395 certified palliative care nurses belonging to facilities in the Kyushu, Chugoku, and Shikoku regions in a document describing the purpose of the study, the content and date of the training, the freedom to voluntarily participate in the study and withdraw consent, and the data encoding and protection of personal information after responses. Certified nurses who were willing to participate in training and cooperate in research entered their name, affiliation, and desired training date in the format created on the Web.

\section{Implementation of Training}

Participants were presented with two candidate dates and selected the most convenient one.

\section{Data Collection}

Data were collected at three time points: before training (baseline: T0), immediately after training (T1), and 3 months after training (T2). Before the start of the training day (T0), participants answered the questionnaire. Immediately after 
Table 1 Training programs

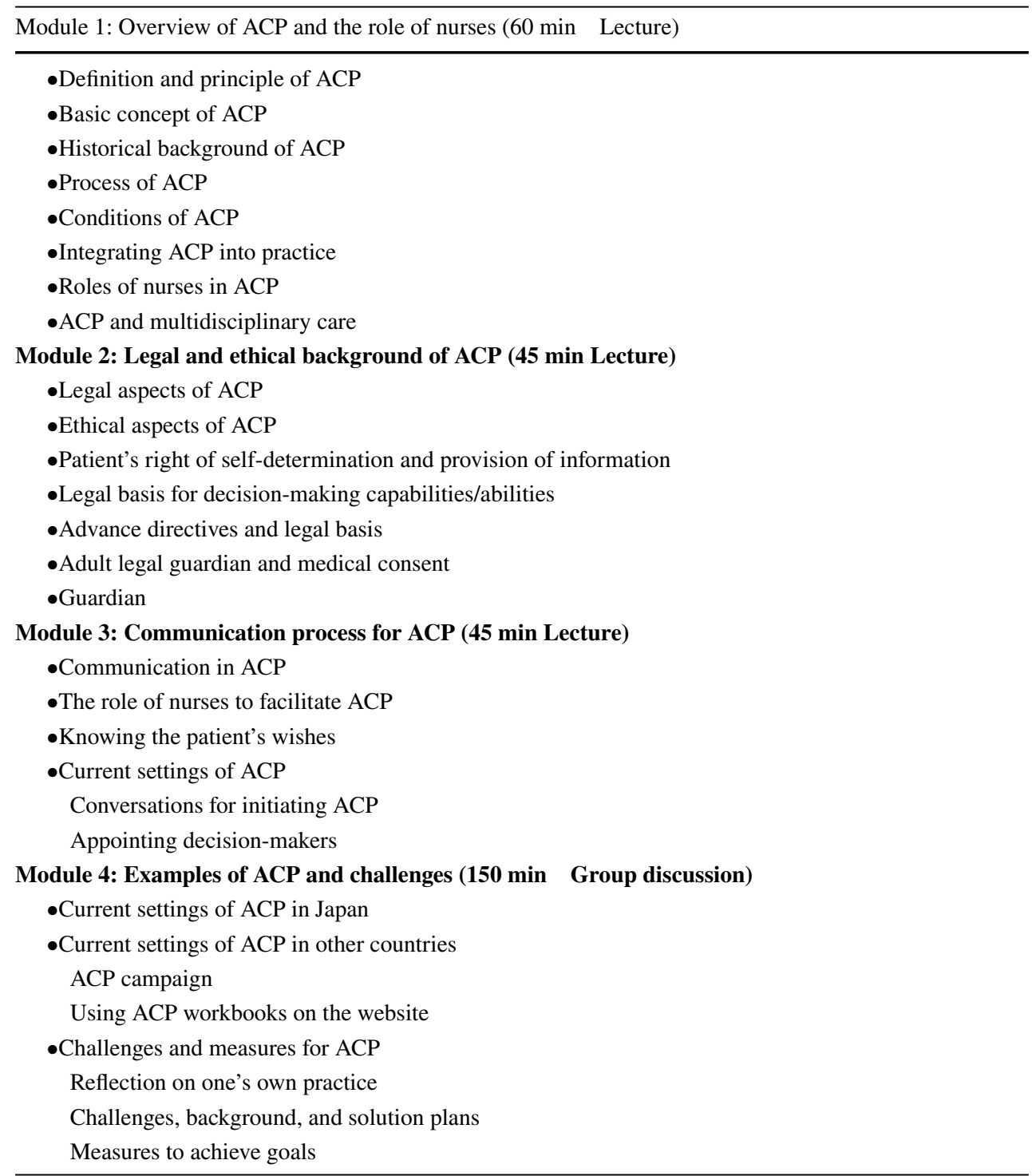

training (T1), the program was evaluated using the questionnaire survey. Three months after the training, participants completed a questionnaire that included the same items as before the training.

\section{Measures}

\section{Primary Outcome of Intervention: ACP Practice}

Thirty-seven items to evaluate ACP for cancer patients were scored on a 5-point Likert scale (1: not practiced at all, 2: not practiced very much, 3: occasionally practiced, 4: sometimes practiced, 5: always practiced). Thirty-seven items are divided into 6 subscales: assessment of patients (4 items), dialogue on ACP among patients/families and medical staff (9 items), clarification of the values of patients (5 items), "facilitate proxy decision-makers' participation in ACP" (4 items), decision-making support for treatment, including life-prolonging treatment ( 7 items), and ACP performance at the time of a reduced decision-making capacity (8 items). The scores for each item were summed, with higher scores indicating more frequent practice.

\section{Secondary Outcome of Intervention: Difficulties with Cancer Nursing Practice}

This scale was created by Onodera et al. [20] to assess the difficulties encountered by nurses practicing cancer nursing using a 6-point Likert scale (1: strongly disagree, 2: slightly disagree, 3: disagree, 4: agree, 5: slightly agree, 6: strongly agree), with higher scores indicating greater difficulty. It consisted of 5 items and 20 sub-items related to ACP, out of 6 items such as communication, knowledge/skills, doctor's treatment/response, medical condition 
explanation/notification, and system/cooperation. The $\alpha$ coefficient of each item was 0.69 to 0.74 .

\section{Secondary Outcome of Intervention: Stages of Change Model}

The stages of change model is a model that categorizes the process of people changing to a desired behavior into five stages. Based on this model [21], we asked the subjects to select the most appropriate response: "I am not thinking of starting within 6 months," "I am thinking of starting within 6 months," "I am thinking of starting within 1 month," "I have been doing this for less than 6 months," and "I have been doing this for more than 6 months.

\section{Evaluation of the Training Program}

Six items were created to evaluate the program structure and training method. In each module, (1) understanding of the content, (2) satisfaction with the content, (3) clarity of the goal, (4) the appropriateness of the content to achieve the goal, (5) appropriateness of the method, and (6) utility for the future practice of ACP were evaluated on a 5-point Likert scale (1: strongly disagree, 2: slightly disagree, 3 : agree, 4: slightly agree, 5 : strongly agree).

\section{Statistical Analysis}

After calculating descriptive statistics for each item, the Wilcoxon signed-rank test was performed to compare the ACP practice scale, difficulty scale for nurses regarding cancer nursing, and $\mathrm{T} 0$ and $\mathrm{T} 2$ data from the stages of change model. The significance of differences was set at $P<0.05$.

\section{Results}

\section{Participant Characteristics}

Daily training was performed twice with 18 and 42 certified nurses in each session. Forty-four out of the 60 participants who underwent the training program responded to the survey 3 months later. We analyzed the responses of 39 participants (65\%), excluding those with missing values. The average age of participants was $43.21 \pm 6.45$ years, and the average years of experience of certified palliative care nurses was $5.05 \pm 3.15$ years (Table 2$)$.

\section{ACP Practice}

In ACP, the average value of $\mathrm{T} 2$ in "Dialogue on ACP among patients, family members, and medical staff"
Table 2 Participant characteristics

\begin{tabular}{|c|c|c|}
\hline & \multicolumn{2}{|c|}{ Participants } \\
\hline & $X$ & SD \\
\hline Age (years) & 43.2 & 6.45 \\
\hline \multirow{2}{*}{$\begin{array}{l}\text { Years' experience as a certified palliative care } \\
\text { nurse }\end{array}$} & 5.0 & 3.15 \\
\hline & $n$ & $\%$ \\
\hline \multicolumn{3}{|l|}{ Sex } \\
\hline Female & 37 & 95 \\
\hline Male & 2 & 5 \\
\hline \multicolumn{3}{|l|}{ Work environment } \\
\hline Palliative care team, full-time & 13 & 33.0 \\
\hline General ward & 12 & 31.0 \\
\hline Palliative care unit & 7 & 18.0 \\
\hline Outpatient department & 3 & 8.0 \\
\hline Admission and discharge assistance & 1 & 2.5 \\
\hline Visiting nurse services & 1 & 2.5 \\
\hline Others & 2 & 5.0 \\
\hline \multicolumn{3}{|l|}{ Official position } \\
\hline Staff & 21 & 54.0 \\
\hline Director & 16 & 41.0 \\
\hline Others & 2 & 5.0 \\
\hline \multicolumn{3}{|l|}{ Workshop experience } \\
\hline Yes & 13 & 33.3 \\
\hline \multicolumn{3}{|l|}{ Educational background } \\
\hline Nursing school & 31 & 79.0 \\
\hline Junior college & 3 & 8.0 \\
\hline University & 5 & 13.0 \\
\hline
\end{tabular}

was significantly higher than the average value of T0 $(p=0.045)$. "Assessment of patients," "Decision-making support for treatment, including life-prolonging treatment." No significant differences were observed between the mean T0 and mean T2 of "confirmation of hope," "promotion of the participation of surrogate decision-makers," and "support for patient decision-making regarding lifeprolonging treatment" (Table 3). Coefficient alpha was "Assessment of patients: 0.76," "Dialogue on ACP among patients/families and medical staff: 0.72 ," "Facilitate proxy decision-makers' participation in ACP: 0.77," "Decisionmaking support for treatment, including life-prolonging treatment: 0.78 ," and "ACP performance at the time of a reduced decision-making capacity: $0.70 . "$

\section{Difficulties with Cancer Nursing Practice}

The average value of T2 for "knowledge/skills" was significantly lower than the average value of T0 $(p=0.001)$. "Communication," "doctor's treatment/response," 
Table 3 Nurses' difficulty scale for caring for cancer patients after ACP practice

\begin{tabular}{|c|c|c|c|}
\hline & \multirow{2}{*}{$\begin{array}{l}\text { Baseline } \\
\text { (T0) } \\
\text { Mean (SD) }\end{array}$} & \multirow{2}{*}{$\begin{array}{l}\text { After } 3 \text { months } \\
\text { Mean (SD) }\end{array}$} & \multirow[t]{2}{*}{$P$-value } \\
\hline & & & \\
\hline \multicolumn{4}{|l|}{ ACP practice or performed (37 items) } \\
\hline Factor 1: Assessment of patients (4) & $13.95(4.48)$ & $14.79(4.03)$ & 0.324 \\
\hline Factor 2: Dialogue on ACP among patients/families and medical staff (9) & $24.49(11.19)$ & $27.59(9.90)$ & 0.045 \\
\hline Factor 3: Clarification of patient values (5) & $20.46(3.51)$ & $20.59(2.84)$ & 0.742 \\
\hline Factor 4: Facilitate proxy decision-makers' participation in ACP (4) & $11.36(3.78)$ & $12.33(3.66)$ & 0.078 \\
\hline Factor 5: Decision-making support for treatment, including life-prolonging treatment (7) & $27.00(5.40)$ & $27.82(5.43)$ & 0.509 \\
\hline Factor 6: ACP performance at the time of a reduced decision-making capacity (8) & $24.23(10.75)$ & $25.97(9.68)$ & 0.741 \\
\hline \multicolumn{4}{|l|}{ Difficulties of nurses practicing nursing for cancer patients (20 items) } \\
\hline Communication (5) & $22.00(3.76)$ & $21.76(3.92)$ & 0.464 \\
\hline Knowledge and skill (1) & $4.85(0.96)$ & $4.3(1.00)$ & 0.001 \\
\hline Collaboration with doctors (4) & $16.02(3.85)$ & $16.17(3.80)$ & 0.679 \\
\hline Disclosure and explanation (4) & $15.41(3.27)$ & $14.66(3.40)$ & 0.134 \\
\hline Hospital system and regional alliances (6) & $27.12(4.20)$ & $26.66(5.02)$ & 0.47 \\
\hline
\end{tabular}

"medical condition explanation/notification." No significant differences were observed between the average values of T0 and T2 for "System/Cooperation" (Table 3).

\section{Stages of Change Model}

The grades of the stages positively changed from T0 to T2 in $19(48.7 \%)$ participants, remained unchanged in $14(35.9 \%)$, and negatively changed in $6(15.4 \%)$.

\section{Evaluation of the Training Program}

Participants were asked about "understanding of the contents," "satisfaction with the contents," "clarity of the goals of the module," "appropriateness of the contents to achieve the goals," "appropriateness of the method," and "future" for all modules. More than $90 \%$ of participants provided positive responses for "usefulness of ACP in practice."

\section{Discussion}

This is the first study in Japan to develop a training program for certified palliative care nurses who practice ACP for cancer patients and clarify its effects. The implementation of the training program increased the dialogue on ACP among patients/family members and medical personnel, which was consistent with previous findings $[11,12]$. A large part of the ACP process consists of dialogue between the patient/ family and healthcare professionals, which is an important component of ACP [12, 14, 15]. Increased dialogue about ACP between participants and patients/families may help promote ACP.
The use of communication models is effective for medical professionals to promote ACP with patients [12, 14, 15]. NURSE, which was adopted in this training program, is used to convey "bad news" and subsequently provide support [19]. In the study, as the participants listened to the patients and their families with reference to the NURSE, the patients' families were able to express their own ideas.

Increased dialogue on ACP among participants and medical professionals contributes to the promotion of ACP in team medical care. ACP for cancer patients in Japan is promoted within the context of team medicine, and nurses play a central role in the team [8], which contributes to the resolution of ACP barriers caused by a lack of communication between teams and departments.

Regarding the difficulties of cancer nursing, the value for "I feel that my knowledge of and skills for ACP are insufficient" was lower 3 months after training than before the training and was attributed to the training program. Therefore, certified nurses recognized that they had acquired knowledge of and skills for ACP. Among the 39 certified nurses who participated in this training program, $26(66.7 \%)$ systematically learned about ACP for the first time. Previous studies also reported that obtaining information on and skills for ACP improved the practice rate of ACP [11, 12].

In the "stages of change model," which surveyed the awareness of certified palliative care nurses of behavioral changes toward ACP, $19(48.7 \%)$ changed to a more positive stage from before training. Thus, knowledge of ACP gained in this training increased the awareness of changing behavior and motivated the participants to take action.

Motivation is important for behavioral changes [21]. Participants conducted group work in training, shared barriers related to ACP, and discussed their solutions and future 
action goals. More than $90 \%$ of the respondents answered positively about the training method and its effectiveness for future utilization; therefore, group work discussions appeared to raise participants' awareness of ACP and motivated behavioral changes. In the future, it will be necessary to incorporate role playing and simulations of different situations and to consider practical training contents and methods that will promote the practice of ACP.

\section{Research Limitations}

The present study has some limitations. Participants in the training program were certified palliative care nurses who belong to facilities throughout Japan, and the sample size is small. In addition, this study had no control group. Therefore, the results obtained cannot be generalized. Further studies are needed to clarify the effectiveness of the program by expanding the target area and implementing the program for a larger number of subjects with using a randomized controlled trial design. Moreover, the present study only investigated the effects of training for up to 3 months after the program. Further studies to evaluate the long-term effects of this training program are needed. In addition, since the number of subjects in the present study was small, it was not possible to perform an analysis that divided data into subgroups or that considered related factors. Another limitation is that the evaluation indicators used in this study did not accurately reflect the effects of the program; therefore, an appropriate evaluation index needs to be developed.

Since the program was for certified palliative care nurses, there may have been little change after taking the program. However, when educating nurses who are not engaged in palliative care, it may be necessary to change the contents and methods of the program. In the future, we would like to develop this program so that nurses who are not engaged in palliative care will also receive ACP training.

Acknowledgements The authors would like to thank Medical English Service (https://www.med-english.com) for the English language editing.

Author Contribution All authors contributed to the study conception and design. Material preparation and data collection and analyses were performed by Yoko Yahiro and Mika Miyashita. The first draft of the manuscript was written by Yoko Yahiro and all authors commented on previous versions of the manuscript. All authors read and approved the final manuscript.

Funding This study was financially supported by JSPS KAKENHI Grant Number JP26463351.

Japan Society for the Promotion of Science,JP26463351,YOKO YAHIRO

Availability of Data and Material The datasets generated and/or analyzed during the present study are available from the corresponding author upon reasonable request.
Code Availability Not applicable.

All procedures performed in studies involving human participants were in accordance the ethical standards of institutions and/or national research committees, and the 1964 Helsinki Declaration and subsequent amendments or equivalent ethics. It complied with the standards.

\section{Declarations}

Ethics Approval. The present study was approved by the Institutional Review Board of Hiroshima University (No. E-2661).

Consent to Participate. Written informed consent was obtained from all participants.

Consent for Publication. All of the authors consented to publishing this manuscript.

Conflict of Interest The authors declare no competing interests.

Open Access This article is licensed under a Creative Commons Attribution 4.0 International License, which permits use, sharing, adaptation, distribution and reproduction in any medium or format, as long as you give appropriate credit to the original author(s) and the source, provide a link to the Creative Commons licence, and indicate if changes were made. The images or other third party material in this article are included in the article's Creative Commons licence, unless indicated otherwise in a credit line to the material. If material is not included in the article's Creative Commons licence and your intended use is not permitted by statutory regulation or exceeds the permitted use, you will need to obtain permission directly from the copyright holder. To view a copy of this licence, visit http://creativecommons.org/licenses/by/4.0/.

\section{References}

1. Emanuel LL, von Gunten CF, Ferris FD (2000) Advance care planning. Arch Fam Med 9(10):1181-1187. https://doi.org/10. 7748/ns.29.39.61.s44

2. Sinuff T, Dodek P, You JJ, Barwich D, Tayler C, Downar J, Hartwick M, Frank C, Stelfox HT, Heyland DK (2015) Improving end-of-life communication and decision making: the development of a conceptual framework and quality indicators. J Pain Symptom Manage 49(6):1070-1080. https://doi.org/10.1016/j.jpainsymman. 2014.12.007

3. Holland DE, Vanderboom CE, Dose AM, Ingram CJ, Delgado A, Austin CM, Green MJ, Levi B (2017) Nurse-led patient-centered advance care planning in primary care. J Hosp Palliat Nurs 19(4):368-375. https://doi.org/10.1097/NJH.0000000000000358

4. Fried TR, Bullock K, Iannone L, O’Leary JR (2009) Understanding advance care planning as a process of health behavior change. J Am Geriatr Soc 57(9):1547-1555. https://doi.org/10.1111/j. 1532-5415.2009.02396.x

5. Brinkman-Stoppelenburg A, Rietjens JAC, van der Heide A (2014) The effects of advance care planning on end-of-life care: a systematic review. Palliat Med 28(8):1000-1025. https://doi.org/ 10.1177/0269216314526272

6. Zhang B, Wright AA, Huskamp HA, Nilsson ME, Maciejewski ML, Earle CC, Block SD, Maciejewski PK, Prigerson HG (2009) Health care costs in the last week of life. Arch Intern Med 169(5):480-488. https://doi.org/10.1001/archinternmed.2008.587

7. Nakazawa K, Kizawa Y, Maeno T, Takayashiki A, Abe Y, Hamano J, Maeno T (2014) Palliative care physicians' practices 
and attitudes regarding advance care planning in palliative care units in Japan: a nation- wide survey. Am J Hosp Palliat Care 31(7):699-709. https://doi.org/10.1177/1049909113507328

8. Yokoya S, Kizawa Y, Maeno T (2018) Practice and perceived importance of advance care planning and difficul- ties in providing palliative care in geriatric health service facilities I Japan: a nationwide survey. Am J Hosp Palliat Care 35(3):464-472. https:// doi.org/10.1177/1049909117723859

9. Inoue M, Hanari K, Hamano J, Gallagher J, Tamiya N (2019) Current engagement in advance care planning in Japan and its associated factors. Gerontol Geriatr Med 5:2333721419892694. https://doi.org/10.1177/2333721419892694

10. Ishikawa T, Fukui S, Okamoto Y (2017) Association between advance care planning by a visiting nurse and achieving the desired place of death for patients with end-stage cancer. J Jpn Acad Nurs Sci 37:123-131. https://doi.org/10.5630/jans.37.123 (In Japanese)

11. Baron K, Hodgson A, Walshe C (2015) Evaluation of an advance care planning education programme for nursing homes: a Longitudinal study. Nurse Educ Today 35:689-695. https://doi.org/10. 1016/j.nedt.2015.01.005

12. Rocque GB, Dionne-Odom JN, Huang CHS, Niranjan SJ, Williams CP, Jackson BE, Halilova KI, Kenzik KM, Bevis KS, Wallace AS, Lisovicz N, Taylor RA, Pisu M, Partridge EE, Butler TW, Briggs LA, Kvale EA, Patient Care Connect Group (2017) Implementation and impact of patient lay navigator-led advance care planning conversations. J Pain Symptom Manage 53:682-692. https://doi.org/10.1016/j.jpainsymman.2016.11.012

13. Barwich D, You J, Simon J, Hanvey L, Hoffman CB (2018) Advance care planning in Canada. In: Thomas K, Lobo B, Detering K (eds) Advance care planning in end of life care. Oxford University Press, Oxford. https://doi.org/10.1093/oso/9780198802 136.003.0019

14 Colville E, Kennedy C (2012) ACP conversations in clinical practice: impact of an education initiative. Br J Community Nurs 17:230-234. https://doi.org/10.12968/bjen.2012.17.5.230
15 Blackford J, Street AF (2013) Facilitating advance care planning in community palliative care: conversation starters across the client journey. Int J Palliat Nurs 19:132-139. https://doi.org/10. 12968/ijpn.2013.19.3.132

16. Tanaka Y, Kizawa Y, Sakashita A (2015) Effectiveness of educational workshop for health care professionals in advance care planning (ACP) and clinical ethics. Palliative Care Res 10(3):310-314. https://doi.org/10.2512/jspm.10.310(InJapanese)

17. Thomas K, Lobo B, Detering K (2018) Advance care planning in end of life care. https://doi.org/10.1093/oso/9780198802136.001. 0001

18. Hansford P, Meehan H (2007) Gold standards framework: improving community care. End of Life Care 1(3):56-61

19. Smith RC (2002) Patient-centered interviewing: an evidencebased method, Subsequent. Lippincott Williams \& Wilkins, Philadelphia

20. Onodera M, Yamauti K, Monma N, Miyashita M, Kumata M, Ogiri N, Asano R, Ogasawara K, Goto A, Shibata H, Syoji Y, Sengoku M (2013) Development of scale to measure nurses' difficulty with cancer care (NDCC). Palliative Care Res 8(2):240-247. https://doi.org/10.2512/jspm.8.240(InJapanese)

21. Matsumoto $C$ (2016) How to motivate client and patient in health guidance and patient education -based with theory of health behavior-. J Jpn Acad Health Behav Sci 31(2):40-45 (In Japanese)

Publisher's Note Springer Nature remains neutral with regard to jurisdictional claims in published maps and institutional affiliations. 